\title{
Controlling Rapid Change through Systems Engineering the Organization
}

\author{
Jairus Hihn \\ Rebecca Wheeler \\ Jet Propulsion Laboratory/ \\ California Institute of Technology \\ 4800 Oak Grove Drive \\ Pasadena, CA 91109
}

\begin{abstract}
A new approach to change management has been developed and applied at the Jet Propulsion Laboratory (JPL). It's main focus is on aligning the organization with the strategic plan; and understanding the internal organizational relationships that impact change, which ultimately determine an organizations ability to be transformed and renewed. The new approach regards the strategic plan of a company as the standard by which progress and achievement are measured. Purposeful interventions should generate a company movement along a strategic course, and tracking that movement is essential for managing change. This paper presents an overview of DYNOMO, or the DYNamic Organizational Model which was developed to assist in the measurement and analysis of organizational state. The paper concludes with summaries of two applications.
\end{abstract}

\section{INTRODUCTION}

In 1993 a series of substantial cuts to the US government budget for the space program made it necessary to radically restructure NASA's unmanned deep space exploration program which is primarily managed by the Jet Propulsion Laboratory (JPL). JPL is a NASA research facility managed by the California Institute of Technology (Caltech) for NASA, and is located in Pasadena, California. These changes called for developing the next generation of deep space missions at a fraction of the cost and schedule of older missions, reducing schedule from 7 years to 2 to 3 years. Management at the Jet Propulsion Laboratory (JPL) stepped up to the challenge by introducing a number of large scale change initiatives designed to realign the organization with the new strategic orientation. In a course of four years, a Total Quality Management program was launched and three major Business Process Reengineering efforts were started.

The research described in this publication was carried out at the Jet Propulsion Laboratory. California Institute of Technology, under a contract with the National Aeronautics and Space Administration

\author{
Haya Zak' \\ SYMANTEC \\ 2500 Broadway Suite 200 \\ Santa Monica, CA 90404
}

In addition, a major increase in the outsourcing of spacecraft production and a number of support functions took place, workforce reductions were sought, groups and sections were completely re-organized, and numerous other change programs were instigated.

JPL's leadership was faced with a flood of internal changes that needed to be integrated and steered in the direction set forth by the company's new strategic goals. The problem was that there were just too many changes happening all at once.

DYNOMO, or the DYNamic Organizational MOdel, was developed at JPL over a period of two years. It was designed to assist JPL's executive leadership in measuring organizational transformation in terms of the company's strategic goals. DYNOMO is a comprehensive framework for analyzing both the actual and future impacts of individual and multiple change initiatives, and for assessing the company's present state.

\section{ORGANIZATIONAL MODEL: DYNOMO}

DYNOMO is a macro organizational model for managers who want to ensure that on going change activities are exerting the right sort of coordinated impacts on their organization. The model incorporates current trends in management and leadership, organizational theory and measurement, requiring an interdisciplinary team for its construction. (SKANDIA, 1994; Kaplan and Norton, 1996; Heckscher and Donnellon, 1994; Alvesson and Berg, 1992; Golembiewski, 1993; Mohrman et. al., 1991; Nolan and Croson, 1995; Simons, 1995; Sink and Tuttle, 1989) For insight into corporate culture the anthropology and sociology fields were also reviewed. (Reuter, 1984, Vivelo, 1978)

In this paper we will be describing the development and application of the static version of DYNOMO. The static model is used to provide a snap shot of the state of the company at a specific time. When designing a new change initiative the model can help in assessing

\footnotetext{
I Haya Zak was an employee of JPL at the time the study was conducted.
} 
the degree to which program objectives support the company's strategic objectives, and in exploring possible outcomes given different implementation scenarios. After the change initiative has already started the model can be used as an organizing framework"for collecting information and making observations on how the program is actually being implemented. Systematic data collection during or following implementation is requisite for understanding the true forces at play. Information organized by the model can be used for analyzing the root causes of observed problems either by applying a formal dynamic version of the model or by a heuristic analysis of how the organizational elements interact.

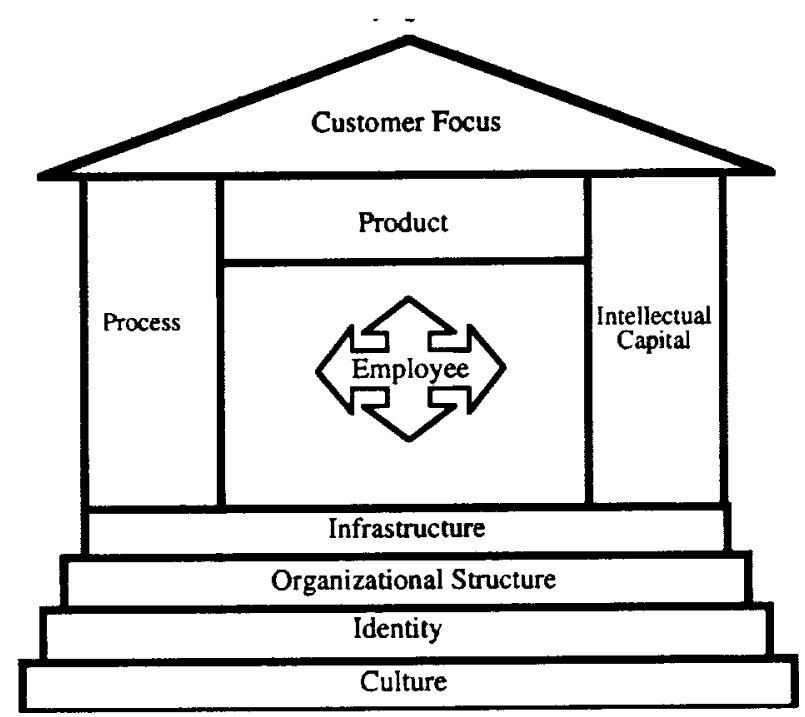

Figure 1: DYNOMO - 'the House'

Building Blocks. Nine organizational elements, which we call building blocks, are used to represent the fundamental components that make up an organization; Customers, Products, Processes, Employees, Infrastructure, Organizational Structure, Culture, Identity, and Intellectual Capital. Together they form 'the house' shown in Figure 1. The only major component intentionally left out is financial performance, the reason being that JPL is a not-forprofit organization. This could be introduced as a new building block or more simply by introducing new descriptors into the customer focus building block. All the building blocks consist of a detailed definition, one or two macro-state variables, and three to four descriptors.

Examples of a some of the building blocks and their elements is provided in figure 2. Concepts represented in building blocks are often complex. For instance, Identity contains both the mission of a company, and the external image projected by the company. Additionally, Identity can be applied to the company but also to sub-groups within the company, as well as to the individual employee.

Many of the concepts we are dealing with work on multiple levels, starting with the company as a whole, and cascading all the way down to the individual employee. DYNOMO can thus be applied at different levels depending on the focus of the analysis.

Building blocks that are influenced by each other are placed in proximity to each other. Dependency is related to the following assumption: the state of a building block is likely to be more affected by the state of an adjacent building block than by the state of a distant building block.

Desired State Descriptors. Company objectives such as commonly found in its strategic plan are used to define a set of descriptors that characterize the desired state for each of the building blocks. Desired state descriptors concisely specify the goal state for a building block, and embed the strategic thinking of company leadership.

For example, the descriptors for the Process building block, 'short cycle time', 'delivers what's needed', and 'always best practices' paint the picture of work processes in the future as faster, simpler, more reliable yet flexible, and that incorporate the best practices from industry.

The current model customized for JPL yields 30 desired state descriptors. Together they depict the vision that JPL leadership currently has for their company. The number and type of descriptors is likely to vary from company to company. Desired state descriptors are defined and grouped into broader categories. A summary of the desired state descriptors is provided in Figure 2a and $2 b$.

\begin{tabular}{|c|c|c|}
\hline Building Block & $\begin{array}{c}\text { Macro State } \\
\text { Variable }\end{array}$ & $\begin{array}{c}\text { JPL Desired State } \\
\text { Descriptors }\end{array}$ \\
\hline $\begin{array}{c}\text { Customer } \\
\text { Focus }\end{array}$ & Responsive & $\begin{array}{l}\text {-high customer } \\
\text { satisfaction } \\
\text {-high partnering } \\
\text {-highly inspired public }\end{array}$ \\
\hline Product & $\begin{array}{c}\text { Value } \\
\text { And } \\
\text { Risk }\end{array}$ & $\begin{array}{l}\text { - Ist of a kind } \\
\text {-high quality } \\
\text {-low cost } \\
\text { - moderate risk }\end{array}$ \\
\hline Process & $\begin{array}{c}\text { Efficient } \\
\text { And } \\
\text { Effective }\end{array}$ & $\begin{array}{l}\text {-short cycle time } \\
\text {-delivers what is needed } \\
\text { - always best practices }\end{array}$ \\
\hline Employee & $\begin{array}{c}\text { Competent } \\
\text { And } \\
\text { Innovative }\end{array}$ & $\begin{array}{l}\text {-highly proficient } \\
\text {-significant breadth } \\
\text {-highly motivated } \\
\text {-creative }\end{array}$ \\
\hline
\end{tabular}

Figure 2a: JPL Desired State Descriptors 


\begin{tabular}{|c|c|c|}
\hline Building Block & $\begin{array}{c}\text { Macro State } \\
\text { Variable }\end{array}$ & $\begin{array}{l}\text { JPL Desired State } \\
\text { Descriptors }\end{array}$ \\
\hline $\begin{array}{l}\text { Intellectual } \\
\text { Capital } \\
\text { infrastructure }\end{array}$ & $\begin{array}{l}\text { Continuous } \\
\text { Organizational } \\
\text { Leaming }\end{array}$ & $\begin{array}{l}\text {-knowledge is extracted } \\
\text { - knowledge is shared } \\
\text {-knowledge is applied." } \\
\text { - best internal services } \\
\text { - quality information is } \\
\text { readily available } \\
\text { - rules are easy to follow }\end{array}$ \\
\hline $\begin{array}{l}\text { Organiza-tional } \\
\text { Structure }\end{array}$ & Supportive & $\begin{array}{l}\text {-appropriate roles } \\
\text { - decentralized authority } \\
\text { and responsibility } \\
\text { - leadership based } \\
\text { management } \\
\text { - supports strategic and } \\
\text { tactical goals }\end{array}$ \\
\hline Identity & Strength - & $\begin{array}{l}\text { - leaders in deep space } \\
\text { exploration } \\
\text { - highly engaged } \\
\text { individuals } \\
\text { - cost competitive } \\
\text { products }\end{array}$ \\
\hline Culture & Open & $\begin{array}{l}\text {-change tolerant } \\
\text { - candid communications } \\
\text {-team oriented }\end{array}$ \\
\hline
\end{tabular}

Figure 2b: JPL Desired State Descriptors

Assessment. The contribution of a change initiative to a desired state is assessed using a five point discrete rating scale shown in Figure 3. Final ratings are formed by aggregating and reconciling subjective judgments made by key players and stakeholders. The use of a standardized rating scale permits getting to the bottom line of every question quickly, while still leaving time for relating personal experiences. It also supports a methodology for combining objective and subjective data.

\begin{tabular}{|c|l|}
\hline Sy mbol & \multicolumn{1}{|c|}{ Interpretation } \\
\hline 0 & Contributes to meeting strategic goals \\
\hline 0 & $\begin{array}{l}\text { Partially Contributes to meeting } \\
\text { strategic goals }\end{array}$ \\
\hline 0 & $\begin{array}{l}\text { Neither contributes nor conflicts with } \\
\text { strategic goals }\end{array}$ \\
\hline 0 & Partial Conflict with strategic goals \\
\hline 0 & Conflicts with strategic goals \\
\hline
\end{tabular}

Figure 3: DYNOMO Descriptor Rating Scale

The information needed can be collected in many different ways including interviews, surveys, team discussions and voting, and document reviews. We used a combination of structured and unstructured interviews combined with document reviews. The appropriateness of a method often depends on cost and schedule considerations.

\section{APPLICATIONS}

Employee Performance Evaluation. The first opportunity to apply the model at JPL presented itself in 1996 with the introduction of a new employee evaluation process. The new process was put in place in 1995. Based on lessons learned in the 95 rollout significant changes were incorporated to the 96 design. DYNOMO analysis took place in the interim period preceding the 96 rollout to evaluate the effectiveness of the 96 version of the process.

A comparative evaluation, using information collected from interviews of key players as well as users affected by the new process, focused on the contribution of the initiative to achieving the desired state of JPL in terms of both its design and its implementation.

Results clearly demonstrated a major improvement in the 96 design. At the same time DYNOMO prognosis for the up and coming implementation was not good. It would appear that the new rollout was going to fall short of meeting JPL's strategic objectives in many critical areas, such as Process efficiency and effectiveness and Employee development. Figure 4 displays a summary of the performance ratings.

\begin{tabular}{|l|c|c|c|c|}
\hline Organization & \multicolumn{2}{|c|}{ ECAP 95 } & \multicolumn{2}{c|}{ ECAP 96 } \\
\hline Building Block & Design & $\begin{array}{l}\text { Out- } \\
\text { come }\end{array}$ & Design & $\begin{array}{l}\text { Out- } \\
\text { come }\end{array}$ \\
\hline Process & 0 & 0 & 0 & 0 \\
\hline Employee & 0 & 0 & 0 & 0 \\
\hline $\begin{array}{l}\text { Intellectual } \\
\text { Capital }\end{array}$ & 0 & 0 & & 0 \\
\hline Infrastructure & 0 & 0 & 0 & $D$ \\
\hline Culture & 0 & 0 & 0 & 0 \\
\hline
\end{tabular}

Figure 4: Employee Performance Evaluation Descriptor Ratings

The information gathered by the DYNOMO analysis team revealed a number of problems. The new process took longer to conduct, and was not supported by information technology. Many of the creative ideas related to career planning, on going performance discussions, and the solicitation of customer and project management inputs for evaluation, were not put into action.

A root cause analysis had identified two major causes, (1) the 'old' culture was still dominating the attitudes and behaviors of technical group supervisors and employees, and (2) a severe work overload was 
precluding technical group supervisors from adequately performing employee evaluation activities.

DYNOMO analysis had helped management identify problems rooted in the larger context, the changing work conditions and culture at JPL. While before, insufficient training or poorly written instruction manuals were automatically blamed, DYNOMO analysis had shown that a significantly more intricate situation was responsible for the actions of managers and employees, one that required a more sophisticated solution than previously thought.

The application of DYNOMO to the new initiative demonstrated the value of DYNOMO analysis in methodically exposing the tensions and conflicts inherent in a changing company that if unattended will damage long term organizational effectiveness.

Flight Project Implementation. JPL is a matrix organization. The matrix consists of line management and project management. JPL had been traditionally organizing and managing flight projects by having the project be responsible for the budgeting and customer interface while the line management was responsible for product development and delivery. Projects would contract with line organizations to acquire needed products and services from them. Line organizations were the principal suppliers of all project needs, be it the development of the spacecraft itself, the scientific instrument onboard, or the telecommunications services during flight.

In 1995, JPL had begun changing the method of organizing and managing the development and implementation of flight projects with the goal of streamlining the mission development process. These changes became known in JPL as the Soft projectization initiative. Soft projectization was proposed as a compromise between hard projectization and giving all authority and responsibility to the projects and the status quo, where the line had the majority of the authority and responsibility.

Informal experiments started several years before this approach to project organization in a matrix environment was formalized. The number of projects using soft projectization greatly increased after this and some projects even partly reorganized. One example being the Cassini project, which is going to Saturn. Cassini is the last of the very large, very complex space craft and in the hope of better controlling cost and schedule it was decided to introduce the use of soft projectization into a number of Cassini's subsystems.

Soft projectization had fundamentally altered the division of labor between line and project by concentrating responsibility for the product development in the project, leaving the line with a limited support function. The line's principal function was to become the long term administration and growth of organizational resources and infrastructure. Organizational short term order fulfillment and long term asset development were being split between the project and the line.

The DYNOMO team began assessing the impact of Soft projectization two years after soft projectization had been formally introduced into JPL. The DYNOMO analysis began by asking two basic questions: (1) is Soft projectization really happening: i.e. Are new roles being fulfilled as specified? and (2) Is Soft projectization contributing to the achievement of JPL's strategic goals?

A comparative case study approach was selected as the analysis methodology. One pilot and four complete cases, representing five elements from five different flight projects were examined by means of in-depth interviews with both project and line managers.

Each interview was conducted using a structured interview format. The format was designed to probe each individual's perspective concerning:

- how soft projectization had been implemented on the element,

- where conflicts had occurred and how they had been resolved (or not),

- how interviewees felt about their own role in relation to the element,

- where improvements or changes in the program were needed; and finally,

- the impact of soft projectization on the JPL organization as a whole relative to the "old way of doing business"

Separate but linked interviews forms were developed for each element role. The intent was to assure that each interviewee discuss how well the PEM and GS role in particular was working within that element, what kinds of conflicts had occurred and how they had been handled. All of the forms were tested and subsequently revised based on discussions with participants from the pilot.

Each interview session was conducted by two interviewers who took notes during the interview. Immediately after the session was completed, each interviewer produced a written summary of part of the interview. They then exchanged their written summaries, added additional notes, reconciled any differences and finalized a single summary of the interview.

A total of 27 interviews were conducted by four different interviewers with participants from the five elements. The interviews within the same element were scheduled as closely together as possible; however, because of scheduling constraints, data from two 
different elements was usually being collected within a given time period.

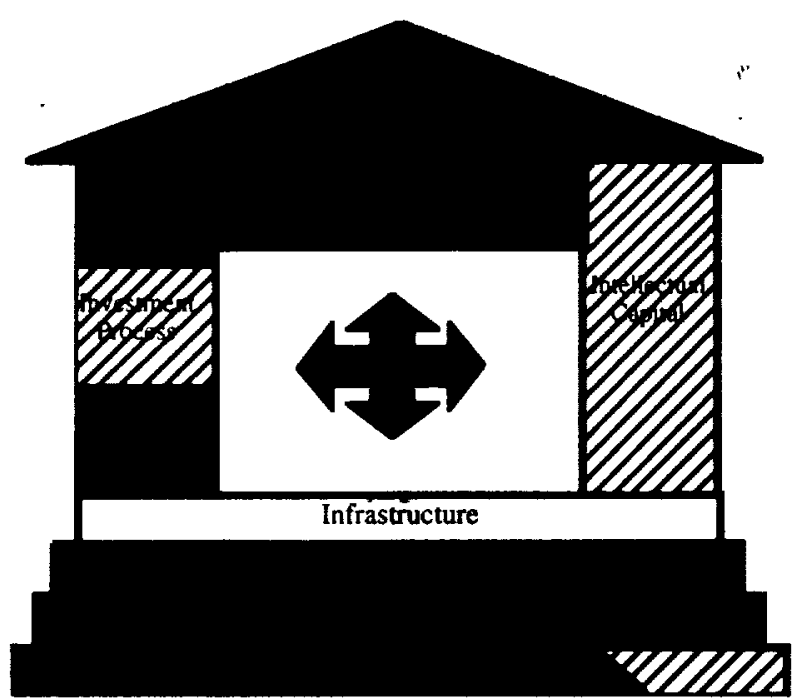

Figure 5: Soft Projectization Current State

\begin{tabular}{|c|c|c|c|}
\hline $\begin{array}{l}\text { Building } \\
\text { Block }\end{array}$ & $\begin{array}{l}\text { JPL. } \\
\text { Desired } \\
\text { Stutc } \\
\text { Descriptor }\end{array}$ & Rating & Rational \\
\hline \multirow[t]{4}{*}{$\begin{array}{l}\text { ORGANI- } \\
\text { ZATIONAL } \\
\text { STRUC- } \\
\text { TURE }\end{array}$} & $\begin{array}{l}\text { appropriate } \\
\text { roles }\end{array}$ & & $\begin{array}{l}\text { SHARFD ROLES ARE NOT BEING } \\
\text { PERFORMFD. } \\
\text { FEW RESOURCES TO SUPPORT } \\
\text { GS'S TRADITIONAL. } \\
\text { RESPONSIBIITIES. } \\
\text { MOST GS 'S ARE VERY } \\
\text { UNHAPPY WITH THEIR } \\
\text { OPPORTUNTTES FOR } \\
\text { TFCHNICAL. CONTRIBUTION } \\
\end{array}$ \\
\hline & $\begin{array}{l}\text { decentralized } \\
\text { authority } \\
\text { and } \\
\text { responsibility }\end{array}$ & & $\begin{array}{l}\text { PEM HAS ALTHORTY, } \\
\text { RESPONSEBU ITY, AND } \\
\text { RESOLRCTS TO DO THE JOB. } \\
\text { IINE IS GENERALLLY LESS } \\
\text { EMPOWERED } \\
\end{array}$ \\
\hline & $\begin{array}{l}\text { leadership } \\
\text { based } \\
\text { Mgmt }\end{array}$ & & $\begin{array}{l}\text { SOFT PROIECTTATION HAS } \\
\text { INABLED PROIECT } \\
\text { I.EADERSHIP BY GIVING THEM } \\
\text { MORE CONTROL. } \\
\text { 1.INT. CONTRIBUTION IS } \\
\text { WEAKENING } \\
\end{array}$ \\
\hline & $\begin{array}{l}\text { supports } \\
\text { strategic } \\
\text { and tactical } \\
\text { goals }\end{array}$ & & 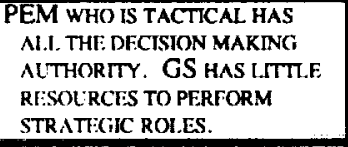 \\
\hline \multirow[t]{2}{*}{ CULTURE } & $\begin{array}{l}\text { candid } \\
\text { communica } \\
\text {-tions }\end{array}$ & & 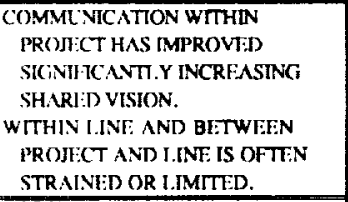 \\
\hline & $\begin{array}{l}\text { team } \\
\text { oriented }\end{array}$ & & $\begin{array}{l}\text { TO0\% OF RESPONDENTS STATTD } \\
\text { THAT HILEMENT TTAMING HAS } \\
\text { IMI'ROVIID WHII.E. INT: } \\
\text { TI:AMING HAS DIECREASED. } \\
\text { TIAM ROTATION }\end{array}$ \\
\hline
\end{tabular}

Table 6a: Mixed Or Negative Organizational Impacts due To Soft Projectization

\begin{tabular}{|c|c|c|c|}
\hline $\begin{array}{l}\text { Buildinys } \\
\text { Blakh }\end{array}$ & 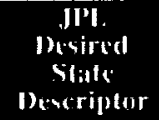 & Kalting & Ruttiunal \\
\hline \multirow{3}{*}{$\begin{array}{l}\text { INTEL- } \\
\text { LECTUAL } \\
\text { CAPITAL }\end{array}$} & $\begin{array}{l}\text { knowledge } \\
\text { is applied }\end{array}$ & & $\begin{array}{l}\text { PEMS ARE EFTECTIVELY } \\
\text { WORKING WITH COST AND } \\
\text { SCHEDUIE CONSTRANTS IN } \\
\text { PRODUCT DEVEI.OPMENT. }\end{array}$ \\
\hline & $\begin{array}{c}\text { new } \\
\text { knowledge } \\
\text { is extracted }\end{array}$ & & $\begin{array}{l}\text { PEM CANNOT CO SEARCHING } \\
\text { IOR NEW INTORMATION, } \\
\text { PROCFSSES, OR TI:CHNOLOGY } \\
\text { DUE TO THE PRESSURES OF } \\
\text { FASTER, BETTER, CHEAPER . } \\
\text { GS WHO USE TO BE THE } \\
\text { CORPORATE MEMORY ARE NOT } \\
\text { CONTRIBUTING TO MOST } \\
\text { FLEMENTS. }\end{array}$ \\
\hline & $\begin{array}{l}\text { knowledge } \\
\text { is shared }\end{array}$ & & $\begin{array}{l}\text { PEM AND ENGINEERS CARRY } \\
\text { KNOWLEDGE FROM PROIECT } \\
\text { TO PROJECT. SOME SIGNS } \\
\text { THAT PEMS ARE SHARING } \\
\text { INFORMATION. } \\
\text { CONFUSIDD RFSFONSIBILITIES } \\
\text { FOR INSTITUTIONAL. } \\
\text { KNOWI.EDGE DEVELOPMENT } \\
\text { BETWEEN LINE, PROJECT, } \\
\text { SPECIAL PROJECTS (E.G. } \\
\text { REENGINEERING TEAMS) }\end{array}$ \\
\hline PROCESS & $\begin{array}{l}\text { delivers } \\
\text { what is } \\
\text { needed }\end{array}$ & & $\begin{array}{l}\text { CONSUMING PROCESSES } \\
\text { PEM 'S TAKE ACCOUNTABILITY } \\
\text { AND TRY TO MAKE THINGS } \\
\text { WORK ANY WAY THEY CAN } \\
\text { INVESTMENT PROCESSIS } \\
\text { LMPLOYIE DFVEL_OPMENT: } \\
\text { LINE FOCUS IS ON TRAINING } \\
\text { WHILF. PROI. FOCUS IS JOB } \\
\text { EXPERITNCE } \\
\text { PROJECTS ARE STARTING TO } \\
\text { THINK MORE CREATTVELY } \\
\text { ABOUT FUTURE. INVESTMENTS } \\
\text { SUPPORT PROCESSES } \\
\text { STAFFING PROCESS IS BROKEN; } \\
\text { CONF.ICTS OVER ASSIGNMENT } \\
\text { ARE AMPLIFIED BY SKII.I.FD } \\
\text { STAFTING SHORTAGES } \\
\text { PEMS COMPI.AN PFRF. EVAL'S } \\
\text { ARE NOT INCENTTVITING } \\
\text { IMPILOYFES }\end{array}$ \\
\hline $\begin{array}{l}\text { INFRA- } \\
\text { STRUC- } \\
\text { TURE }\end{array}$ & $\begin{array}{l}\text { best } \\
\text { internal } \\
\text { services }\end{array}$ & & $\begin{array}{l}\text { LACK OF INFRASTRLCTIRE } \\
\text { SUPPORTING } \\
\text { OFICE AND FAC. AILOCATTON } \\
\text { TESTING, IAB AND DRAFTING } \\
\text { SERVICFS, ETC. } \\
\text { IAB IS NOT MOVING FAST } \\
\text { ENOUGH IS ASSICNING ALL. } \\
\text { RESOURCES TO CRTTCAI. TIME } \\
\text { CONSTRAINED PROITCTS }\end{array}$ \\
\hline
\end{tabular}

Table 6b: Mixed or Negative Organizational Impacts due to Other Factors

Results indicated that although Soft projectization was fundamentally successful at meeting customer requirements, its success was contingent upon the commitment, if not the heroics of project and element managers who were receiving inadequate support from the line. An analysis of the roles and activities being performed revealed that many of the line activities were either not performed at all or taken over by the project. This shown in Figure 5 by the customer, product and 
consuming processes being green while most of the supporting organizational building blocks are red.

Ratings of desired state descriptors gathered in interviews confirmed these findings. Figures $6 \mathrm{a}$ and $6 \mathrm{~b}$ show the information from which the ratings were derived for the building blocks that were in conflict with JPL's strategic plan. Ratings express a shared concem for organizational assets and the maintainability of infrastructure and the employee in the future.

A root cause analysis was performed (see Figure 7 ) which concluded that the entire organization was going to turn red. Dysfunctional support functions, such as the allocation of facilities and staffing, were already taking a toll on the projects, and unless corrected would lead to a crisis. The -growth and upkeep of organizational knowledge assets was being threatened by a number of contributing factors including tighter project schedules, increased workloads, staffing shortages and a lack of a clear vision. A major crises was identified as in the making with respect to the first level of line management, the technical group supervisor, who was experiencing a loss of identity and a loss of a mission. Technical group supervisors no longer had a clear view of, nor did they actually care for their new responsibilities. A limited administrative support role could not take the place of a previously held technical leadership role.

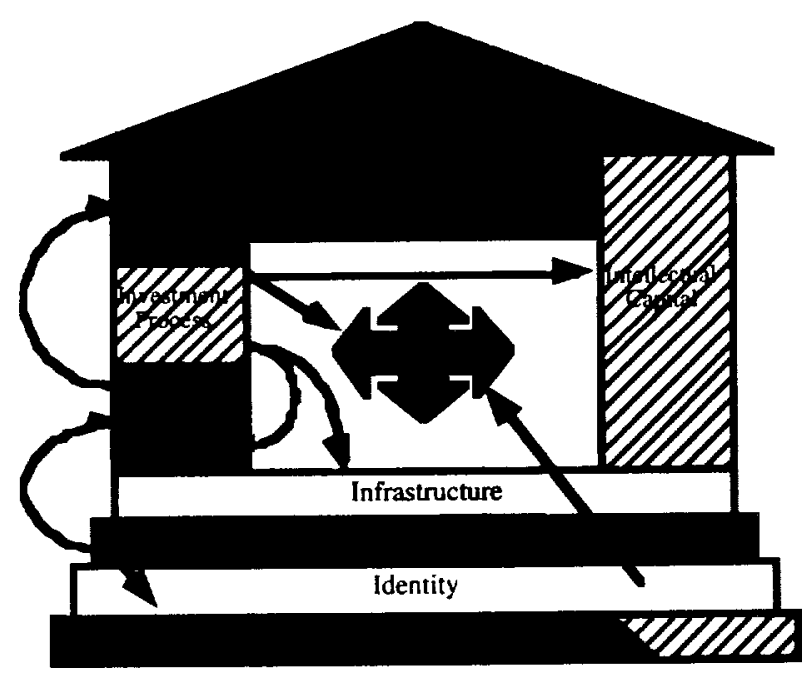

Figure 7: Potential Dynamics

The shift in responsibilities to the PEM has changed the role of the GS from technical decisionmaking to technical oversight. While the PEM interviews documented consistency in how PEMs are doing their jobs, the GS job has become highly variable. As a group. GSs reported a variable mix of technical responsibilities to the element and an assorment of other technical, administrative, staffing, development and conflict-resolution roles. They also had group sizes of 20-30 and different incentive systems for carrying out these roles. Most stated that they were unhappy with their current roles under soft projectization.

The organizational analysis using DYNOMO suggested that an internal dynamic could be activated by providing a clear and meaningful mission for the GS (see Figure 8 ). This was very likely to not only keep the entire organization from going red but might even cause it to go entirely green or be in alignment with JPL's strategic plan.

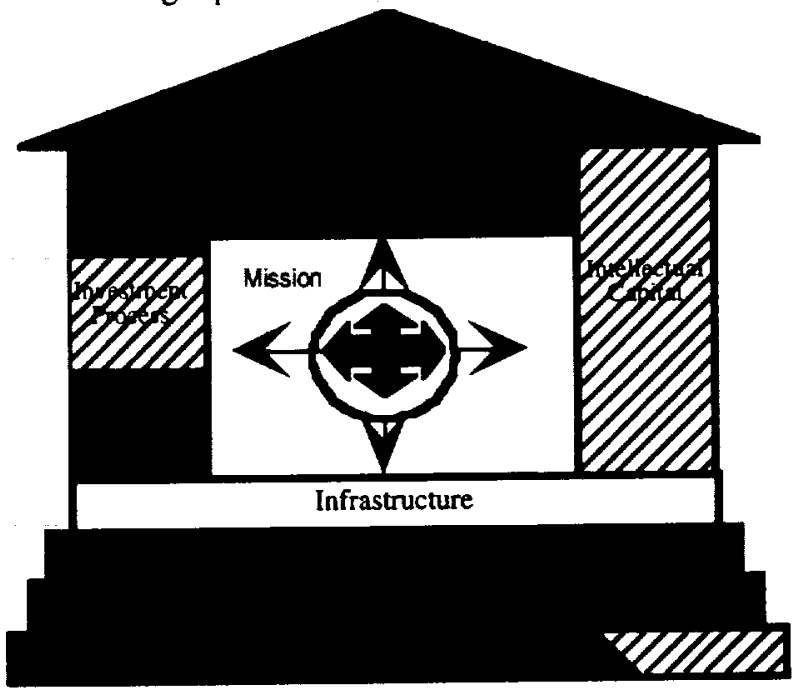

Figure 8: Mission Provides Vision

The defining of a new mission for the GS lead to two recommendations that could allow GS's to have appropriate, clearly defined technical responsibilities to the element. Both recommendations involve creating new roles on the element: technical advisor and the senior of a junior-senior pair.

Technical advisors - would negotiate with projects for timely and specific technical reviews of the element product. Projects would fund this position and no longer fund the individual oversight role traditionally practiced by GSs.

Junior-Senior Pair - would allow projects to have greater access to certain technical skills by using, not one person, but two: a very experienced technical staff member (the senior) and a less-experienced staff member (the junior). The senior would be accountable for the final product; the junior would actually perform the technical work, produce the product, and be the primary project interface, with guidance from the senior. The senior engineer would have several such junior-senior pairings on several projects. 


\section{CONCLUSIONS}

Companies who desire to manage change, rather than simply react to it when it can no longer be ignored, must become knowledgeable, not only about the external forces and constraints operating upon their organization, but also about the internal forces operating within. This is not an easy task as the internal forces are embedded as much in employee attitudes and shadow systems as they are in the organizations formal processes and systems. This is why change management has become one of the most challenging and least understood roles facing today's corporate leaders. The use of formal models is one approach to come to grips with change management

Unfortunately, models are rarely used in guiding management decisions except in the areas of market and financial analysis. This is even true at JPL where the majority of managers have highly sophisticated technical backgrounds. The reason is that it requires a significant time investment on the part of a manager to develop sufficient understanding of a model to trust its results. Few if any managers have this amount of time unless they are the original model developers. A major advantage of DYNOMO is that while it is a model it is a very simple one. DYNOMO's main focus is on the systematic organization of information. There are no equations hiding within the model whose assumptions drive the results. There is only data. DYNOMO organizes large amounts of data so that it can be effectively brought to bare on key organizational "problems".

Second, that in the hands of an experienced interdisciplinary team of analysts the model can be turned into a valuable diagnostic tool revealing both potential and actual deviations from the strategic course, and exposing their underlying causes. Using a model such as DYNOMO for steering a company through multiple change initiatives contributes to long term organizational learning

\section{BIBLIOGRAPHY}

Alvesson, M. and Berg, P.O., Corporate Culture and Organizational Symbolism: An Overview, Walter de Gruyter, 1992.

Charles Heckscher and Anne Donnellon, editors, 'The Post-Bureaucratic Organization - New Perspectives on Organizational Change'.Sage publications Inc., 1994

Golembiewski, R.T., ed.,Handbook of Organizational Behavior, Marcel Dekker, Inc., 1993.
Intellectual Capital: A Strategic Inquiry by_Paradigm Pioneers, Skandia, 1994.

Kaplan, R. and Norton, D., The Balanced Score Card, Harvard Business School Press, 1996

Mohrman A.M., Mohrman, S.A., Ledford, G.E., Cummings, T.G., and Lawler, E.E., and Associates, Large Scale Organizational Change, Jossey-Bass Publishers, 1991.

Nolan, R.L. and Croson, D.C.,Creative Destruction: A Six-Stage Process for Transforming the Organization, Harvard Business School Press, 1995.

Reuter, E.B., Handbooks of Sociology, Century Bookbinding, 1984.

Simons, R., Levers of Control: How Managers use Innovative Control Systems to Drive Strategic Renewal, Harvard Business School Press, 1995.

Sink, D.C and Tuttle, T.C., Planning and Measurement in Your Organizations of the Future, Industrial Engineering and Management Press, 1989.

Vivelo, F.R., Cultural Anthropology Handbook, McGraw Hill, 1978.

\section{BIOGRAPHIES}

Name (INCOSE contact):

Dr. Jairus M. Hihn

Business Affiliation: JPL

Business Address: 4800 Oak Grove

Drive, Pasadena, CA 91109

Phone Number: (818) 354-1248

Fax Number: (818) 393-9815

E-mail address: jhihn@jpl.nasa.gov

Biography: Jairus $M$. Hihn is a senior economist at the National Aeronautics and Space Administration's Jet Propulsion Laboratory. His research interests include the identification and use of quantitative measures and techniques for mission and software cost forecasting as well as in support of organizational change management activities. He has participated in mission and software cost analysis of numerous NASA space projects including JPL's Deep Space Network and the Mars Pathfinder mission. The work reported here was completed while working as part of a team at JPL which provided technical support for change management activities. He received his M.A. and $\mathrm{Ph}$. $D$. in economics from the University of Maryland, and was an assistant research economist at the University of California at Berkeley. Before joining JPL, Hihn was with the Xerox Artificial Intelligence Systems Business Unit. 


\section{CONCLUSIONS}

Companies who desire to manage change, rather than simply react to it when it can no longer be ignored, must become knowledgeable, not only about the external forces and constraints operating upon their organization, but also about the internal forces operating within. This is not an easy task as the internal forces are embedded as much in employee attitudes and shadow systems as they are in the organizations formal processes and systems. This is why change management has become one of the most challenging and least understood roles facing today's corporate leaders. The use of formal models is one approach to come to grips with change management

Unfortunately, models are rarely used in guiding management decisions except in the areas of market and financial analysis. This is even true at JPL where the majority of managers have highly sophisticated technical backgrounds. The reason is that it requires a significant time investment on the part of a manager to develop sufficient understanding of a model to trust its results. Few if any managers have this amount of time unless they are the original model developers. A major advantage of DYNOMO is that while it is a model it is a very simple one. DYNOMO's main focus is on the systematic organization of information. There are no equations hiding within the model whose assumptions drive the results. There is only data. DYNOMO organizes large amounts of data so that it can be effectively brought to bare on key organizational "problems".

Second, that in the hands of an experienced interdisciplinary team of analysts the model can be turned into a valuable diagnostic tool revealing both potential and actual deviations from the strategic course, and exposing their underlying causes. Using a model such as DYNOMO for steering a company through multiple change initiatives contributes to long term organizational learning

\section{BIBLIOGRAPHY}

Alvesson, M. and Berg, P.O., Corporate Culture and Organizational Symbolism: An Overview, Walter de Gruyter, 1992.

Charles Heckscher and Anne Donnellon, editors, 'The Post-Bureaucratic Organization - New Perspectives on Organizational Change'.Sage publications Inc., 1994

Golembiewski, R.T., ed.,Handbook of Organizational Behavior, Marcel Dekker, Inc., 1993.
Intellectual Capital: A Strategic Inquiry by_Paradigm Pioneers, Skandia, 1994.

Kaplan, R. and Norton, D., The Balanced Score Card, Harvard Business School Press, 1996

Mohrman A.M., Mohrman, S.A., Ledford, G.E., Cummings, T.G., and Lawler, E.E., and Associates, Large Scale Organizational Change, Jossey-Bass Publishers, 1991.

Nolan, R.L. and Croson, D.C.,Creative Destruction: A Six-Stage Process for Transforming the Organization, Harvard Business School Press, 1995.

Reuter, E.B., Handbooks of Sociology, Century Bookbinding, 1984.

Simons, R., Levers of Control: How Managers use Innovative Control Systems to Drive Strategic Renewal, Harvard Business School Press, 1995.

Sink, D.C and Tuttle, T.C., Planning and Measurement in Your Organizations of the Future, Industrial Engineering and Management Press, 1989.

Vivelo, F.R., Cultural Anthropology Handbook, McGraw Hill, 1978.

\section{BIOGRAPHIES}

Name (INCOSE contact):

Dr. Jairus M. Hihn

Business Affiliation: JPL

Business Address: 4800 Oak Grove

Drive, Pasadena, CA 91109

Phone Number: (818) 354-1248

Fax Number: (818) 393-9815

E-mail address: jhihn@jpl.nasa.gov

Biography: Jairus $M$. Hihn is a senior economist at the National Aeronautics and Space Administration's Jet Propulsion Laboratory. His research interests include the identification and use of quantitative measures and techniques for mission and software cost forecasting as well as in support of organizational change management activities. He has participated in mission and software cost analysis of numerous NASA space projects including JPL's Deep Space Network and the Mars Pathfinder mission. The work reported here was completed while working as part of a team at JPL which provided technical support for change management activities. He received his M.A. and $\mathrm{Ph}$. $D$. in economics from the University of Maryland, and was an assistant research economist at the University of California at Berkeley. Before joining JPL, Hihn was with the Xerox Artificial Intelligence Systems Business Unit. 
Name: Dr. Haya Zak

Afnliation: SYMANTEC

Address: 2500 Broadway, suite 200,Santa Monica, CA 90404

Phone Number: (310) 449-4247

Fax Number:

E-mail address: Haya.Zak@ Symantec.com

Biography: Received a BA from University of Tel Aviv, Israel majoring in Philosophy and Social Sciences in 1986, an MS from UCLA, CA in Man Machine Systems Engineering in 1989, and a PhD from UCLA, CA in . Engineering. Dissertation topic of research was Executive Information Systems: how much feedback do managers really need. Worked at JPL, performing research and designing a computer assisted training tool for the training of human operators of teleoperated systems. Also designed and implemented measurement of organizational and process performance. Currently working with Symantec corporation as a Group Program Manager. In current position responsible for the end-to-end development of Nortron Anti-Virus for Lotus Notes on OS/2, Solaris, AIX, $A S / 400$ and $S / 309$. Additionally responsible for the development and mentoring of other program managers at Symantec.
Name: Rebecca Wheeler

Business Affiliation: JPL

Business Address: 4800 Oak Grove

Drive, Pasadena, CA 91109

Phone Number: (818) 354-1249

Fax Number: (818) 354-9876

E-mail Address: rwheeler@jpl.nasa.gov

Biography: Ms. Wheeler began her professional career as an experimental researcher, studying the attributes of learning and memory in both animals and humans. She later moved on to the field of enviromental analysis, working primarily in the areas of energy use impacts and risk analysis. In recent years she has gravitated towards measuring individual and business systems effectiveness with the objective of developing efficiency and effectiveness metrics for nonprofit organizations. Ms. Wheeler has a BA in physiology from UC Berkley, an MA in psychology from Cal State Northridge and an MA in Urban Planning from UCLA 